\title{
Difusão de inovações: apreciação crítica dos estudos de Rogers
}

\section{RESUMO}

A difusão de inovações tem sido uma das atribuições mais visíveis e atuais da Comunicação Social, porém não se observam discussões epistemológicas mais intensas sobre esse assunto. Há uma série de obras e marcos teóricos que abordam a difusão de inovações, sendo uma das obras referenciais o estudo de Everett Rogers: "Diffusion of Innovations". O objetivo desse artigo é discutir a obra de Rogers à luz da crítica da comunicação social utilizando a pesquisa bibliográfica e documental. A análise de "Diffusion of Innovations" revelou que a obra não atende plenamente as atuais demandas sociais e comunicacionais atreladas ao tema, merecendo uma revisão conceitual mais abrangente e profunda tendo em vista as atuais configurações da Comunicação Social.

\section{PALAVRAS-CHAVE}

- difusão de inovações

- comunicação e inovação

- Everett Rogers

\section{ABSTRACT}

The diffusion of innovations has been one of the most visible attributions of Social Communication. However, we do not observe intense epistemological discussions on this subject. There is a lot of research and theoretical studies on the diffusion of innovations. One of the most important being "Diffusion of Innovations" by Everett Rogers. The objective of this article is to discuss the studies of Rogers under a critical view of communication by means of a bibliographic research and documental method. The analysis of "Diffusion of Innovations" shows that Roger's studies are not sufficient to the current social and communication demand on diffusion of innovations. So, it is necessary to a deep conceptual revision of the current configurations in this area.

\section{KEY WORDS}

- diffusion of innovations

- communication and innovation

- Everett Rogers

\section{Gino Giacomini Filho USP}

\author{
Elias Estevão Goulart, \\ IMES
}

\section{Mônica Pegurer Caprino IMES}

U m dos campos mais identificados com a comunicação social tem sido o relacionado à difusão de inovações. São estudos que mostram a relevância da comunicação para que idéias, produtos e avanços sociais possam ser partilhados, consumidos e usufruídos por uma população. As inovações, para serem socializadas, precisam da difusão, que assume características específicas que, corretamente trabalhadas, podem auxiliar nos objetivos de organizações inovadoras, quer sejam governos, empresas ou entidades que produzem ciência e tecnologia.

Considerando a literatura sobre teoria da comunicação, é possível verificar que os estudos de difusão de inovações podem estar alocados em diferentes escolas e em quase todos os temas de comunicação social, já que o conceito e o âmbito da difusão ou disseminação de inovações se confunde com próprio processo da comunicação humana.

No entanto, é possível observar que a escola funcionalista tem sido grande referencial para tais estudos, talvez em parte por seu berço ter sido nesta direção e porque sua aplicação técnica nos setores empresariais demandem uma orientação pragmática. No entanto, a difusão de inovações assume importância além dos objetivos organizacionais e tecnológicos, interagindo e associando-se aos interesses sociais.

Não é uma posição consensual, mas há autores que inserem a difusão de inovações nas teorias sobre os efeitos sociais da comunicação de massa, mais precisamente nas teorias das mediações dos relacionamentos sociais (DeFELUR e BALL-ROKEACH, 1993; McQUAIL, 1994) por entenderem que o tema tenha como suporte principal o sistema social em que a comunicação de uma inovação ocorre.

Considerando parte significativa da produção científica nessa área, surgem como obras referenciais os estudos de Everett Rogers (Blackwell et al, 2005), consolidados e atualizados no livro Diffusion of Innovations (2003). Essa obra, originalmente publicada em 1962, foi recebendo novas edições e atualizações, sendo a última publicada em 2003. Em 1990, o Institute for Scientific Information considerou Diffusion of Innovations como "Citação Clássica”, uma vez que tinha até então cerca de 7 mil citações em artigos publicados em periódicos científicos (ROGERS, 2003).

Portanto, considerado a relevância dessa obra, podemos tê-la como referência para avaliar, em parte, como se adequariam os estudos de difusão de inovação tendo em vista o contexto da comunicação e da sociedade atual.

Assim, propomos como problema central desse artigo discutir se os estudos de difusão de inovação, 
referenciados pela obra Diffusion of Innovations, atenderiam a algumas críticas embasadas em conhecimentos atuais da comunicação social.

Embora sejam referências para muitos trabalhos, os estudos de Rogers vêm merecendo aceitação e também críticas (MATTELART e MATTELART, 1999), algo que tem feito o próprio autor aperfeiçoar seu trabalho.

O objetivo proposto é o de discutir a obra Diffusion of Innovations à luz da crítica da comunicação social, requerendo para isso a pesquisa documental da obra de Rogers e pesquisa bibliográfica, objetivando estabelecer conexões críticas entre o campo da Comunicação Social e a Difusão das Inovações. Para que a base crítica sobre a obra de Rogers esteja em patamar análogo, iremos nos apegar apenas a estudos que tenham certa afinidade com a linha funcionalista.

Outro objetivo desse artigo será o de contribuir com a discussão que tal tema merece. Segundo Rogers (2003), a área de Comunicação representa 15\% da produção científica em Difusão de Inovação, enquanto Marketing e Administração representam 16\%. Estas duas áreas só são ultrapassadas pela Sociologia Rural (20\%).

Dois aspectos ainda podem ser destacados. O primeiro se refere ao vínculo de Rogers com a área de comunicação, pois embora o início de seu trabalho estivesse alinhado com a área de sociologia rural, desde os anos 60 do século $\mathrm{XX}$ vem atuando em departamentos de comunicação de diferentes universidades, sendo sua mais recente atuação no Departamento de Comunicação e Jornalismo da Universidade do Novo México. O outro aspecto se refere ao "status" teórico de Diffusion of Innovations. Conquanto muitos autores apresentem os estudos de Rogers como "Teoria" da Difusão de Inovações (LEE e SCHUMANN, 2002; SURRY, 1997; FRANK et al, 2004), o próprio autor não tem denominado seus estudos como "teoria", razão pela qual também não o faremos, embora esses estudos tenham ingredientes típicos de teorias da comunicação de massa, incluindo pesquisas e modelos.

\section{"Difusão" ou "difusão de inovações"?}

A apreciação crítica da obra Diffusion of Innovations, de Everett Rogers (2003), pode ser iniciada a partir do próprio conceito que o autor faz de Difusão:

Diffusion is the process in which an innovation is communicated through certain channels over time among the members of a social system (p. 5).

Difusão é o processo pelo qual uma inovação é comunicada por certos canais durante um certo tempo, dentre os membros de um sistema social (tradução livre).
O questionamento que pode ser feito a esse conceito é no sentido de que o autor usa o termo "difusão para atribuir-lhe o sentido da própria comunicação de uma inovação ou novas idéias. "Difusão" parece ser mais adequado para caracterizar uma parte do processo da comunicação, qualquer que seja a comunicação, mesmo de idéias que não sejam novas. Boudon e Bourricaud também posicionam a difusão como parte do processo da comunicação: " Chama-se difusão o processo pelo qual uma informação [...], uma opinião, uma atitude ou uma prática (por exemplo, a utilização de uma nova técnica agrícola ou de uma prática anticoncepcional) se expandem numa população dada" (2001, p. 161).

O conceito de "difusão" sugerido por Rogers parece ser mais adequado para qualificar a expressão "Difusão de Inovações".

Aliás, Rogers, ao atribuir tal conceito para "difusão", torna o termo equivalente à "comunicação". Isso porque ele tipifica "difusão" como "processo" comunicacional. Berlo (1999), por exemplo, lembra que a comunicação é um processo e, por isso, é inadequada qualquer análise ou compartimentação que se faça dos elementos que o integram. Berlo exemplifica o teatro como um processo, envolvendo dramaturgo, peça, diretores, atores, auxiliares técnicos, espectadores, cenários, luzes, sala, além das inter-relações dinâmicas entre as partes e fases. Talvez, por ser difícil separar a "difusão", que caracteristicamente se refere à expansão, propagação (STRAUBHAAR; LaROSE, 2004), distribuição ou disseminação de inovações, do processo de comunicação, tenha usado atributos próprios da ação comunicacional, mesmo que esse extrapole características difusionistas.

Essa indecisão de nomenclaturas (difusão ou comunicação) deve ter ocorrido também com Rogers. Isso porque, embora seu primeiro livro em 1962 tenha sido Diffusion of Innovations, a segunda edição em 1971 trouxe o título Communication of Innovations: A Cross Cultural Approach, autoria essa compartilhada com F. Floyd Shoemaker. As edições seguintes (1983, 1995 e 2003) retomaram a denominação Diffusion of Innovations. Quando Rogers atribui ao conceito de "difusão de inovação" elementos que integram todo o processo em que uma inovação é comunicada, gera a expectativa de que tal conteúdo enverede para todas direções que caracterizam esse processo, caso de se aprofundar no conteúdo da mensagem, análise de sistemas culturais da sociedade e das organizações (HARGIE e TOURISH, 1996), além de incursões sobre como os aspectos políticos e ideológicos interagem com a difusão das inovações. Porém, nenhum desses temas é razoavelmente contemplado por Rogers.

\section{Inovação: onde estaria o foco?}

Outro ponto do trabalho de Rogers que pode merecer uma análise crítica é o conceito atribuído à inovação: 
An innovation is an idea, practice, or object that is perceived as new by an individual or other unit of adoption (p. 12).

Uma inovação é uma idéia, prática, ou objeto que é percebido como novo por um indivíduo ou outra unidade de adoção (tradução livre).

Tal apresentação conceitual parece assumir o grau elevado de complexidade que o termo requer. Isso porque extrapola a inovação como algo meramente tecnológico, atribuindo essa condição não somente para o ineditismo da idéia em si, mas seu real impacto social, já que uma novidade, não sendo "percebida" como nova, tem suas propriedades inovadoras praticamente anuladas.

Ao condicionar a inovação como algo "percebido" como novo, Rogers envereda-se pelo campo das teorias da aprendizagem, que tem desenvolvido substanciais estudos sobre "percepção". Para Bock: “A percepção é, pois, um processo que vai desde a recepção do estímulo pelos órgãos dos sentidos até a atribuição de significado ao estímulo" (2001, p. 136). Portanto, uma pessoa pode ser estimulada com uma nova tecnologia ou idéias inovadoras, mas que apenas serão inovações se essa pessoa, dentro de seu universo cognitivo, atribuir significado de inovação, podendo a partir daí aceitar ou rejeitar sua apropriação.

Hockenbury e Hockenbury corroboram com tal significado: "A percepção acontece quando integramos, organizamos e interpretamos as informações sensoriais de forma significativa" (2003, p. 82). Porém os mesmos autores alertam que: "As nossas experiências educacionais, culturais e de vida modelam aquilo que percebemos" (idem, p. 114).

Nesse ponto, Rogers parece mostrar fragilidades no seu trabalho, pois o autor não foca os interesses pessoais, culturais, políticos, ideológicos e mercadológicos das inovações, embora seja minucioso sobre o impacto que os grupos sociais geram nos indivíduos para que aceitem ou rejeitem inovação.

$\mathrm{O}$ autor pouco discute a adequação das inovações organizacionais à realidade e desejo individual em que uma pessoa tenha livre arbítrio de adotar ou não uma inovação. Não critica o modelo cultural dos países ricos, sobre o qual repousa boa parte das "inovações" e que servem de modelo a outros paises, tornando a inovação um fator de dependência pessoal e coletiva.

A sociedade digital pode ser um instrumento fabuloso de igualitarismo sem a necessidade de aniquilar a pluralidade de opções e propostas. Mas pode converter-se, também, numa forma ampliada de dominação. Aqui está o mais sublime e aterrador dos paradoxos de nossa existência moderna. O homem, inventor e dono da tecnologia, contempla hoje a ameaça de converter-se em seu escravo (CEBRIÁN, 1999, p. 154.).
Assim, Rogers, ao contrário do que prevê seu conceito de inovação, não conduz seu estudo focando o universo cognitivo e sócio-cultural das pessoas, uma vez que por essa mesma conceituação, são as pessoas, em função de como "percebem" a novidade, é que dão sentido à inovação e condicionam sua difusão. Os onze capítulos da obra de Rogers (2003) destinam-se a apresentar o fenômeno da inovação enquanto algo sistêmico, privilegiando os aspectos epistemológicos e tecnológicos das inovações, a forma como a inovação é processada pelas pessoas e grupos sociais (e suas conseqüências), e como as organizações conduzem a inovações. Esses conteúdos mostram-se alinhados com uma abordagem "fisiológica", mesmo ainda os assuntos que possuem desdobramentos sociais.

Rogers, na seção "Elementos de Difusão", focaliza o processo básico como ocorre a difusão da inovação. Nessa parte, chega a discutir os "atributos de inovações percebidos", porém atém-se a aspectos operacionais, como vantagens obtidas pela pessoa ao adotar uma inovação, compatibilidade com seus valores, complexidade para adotar a inovação, viabilidade (possibilidade de proveito dentro dos limites da realidade pessoal) e observabilidade em que os resultados são visíveis.

Portanto, o que apontamos aqui é uma possível distorção do que Rogers enuncia como conceito de inovação e o tratamento que sua obra dispensa a esse conceito, que demandaria um foco intenso nas pessoas e sociedade, caso de questões culturais, políticas e ideológicas, que condicionam a forma como uma novidade é percebida. Tal enfoque poderia fugir de um sentido utilitarista e manipulador, considerando que as inovações deveriam servir à sociedade, e não prioritariamente a empresas e governos.

\section{Inovação e marketing social}

A forma como ocorre a difusão de uma inovação pode envolver interesses manipulativos. Grupos, empresas, governos podem fazer uso de técnicas de difusão de inovações para chegar a propósitos ilícitos, como ocorreu, por exemplo, com a empresa Nestlé no princípio dos anos 70 do século XX (HARTLEY, 1990). Nesse caso, a empresa utilizou uma série de ações de marketing (ou marketing social) para difundir seu leite em pó utilizando, inclusive, apelos posicionando-o como sucedâneo do leite materno.

Rogers mostra a legitimidade do marketing social na difusão de inovações, inclusive quando as inovações são impostas, caso do uso de capacete para motociclistas, cinto de segurança para motoristas e restrição ao consumo de cigarro pelos fumantes em determinados locais. Segundo o mesmo autor, são tarefas do marketing social, que recentemente tem sido aplicado na conservação de energia, restrição ao fumo, segurança no trânsito, declínio da mortalidade infantil e prevenção à Aids.

$\mathrm{O}$ autor enfatiza que muitas dessas ações são in- 
convenientes para determinadas pessoas, mas que estas são coagidas a adotar para o bem próprio e coletivo. No entanto, o autor admite que o marketing, no campo da inovação, possui vantagens e desvantagens. Um dos aspectos é o ético, quando os profissionais do mercado dão mais prioridade para suas necessidades (ou de suas organizações) do que dos consumidores.

Porém, Rogers não vai muito além dessas observações. $\mathrm{O}$ autor não discute obsolescência programada gerada por inovações (HAUG, 1997), o impacto das constantes inovações para criar necessidades sociais supérfluas e gastos desnecessários (GALBRAITH, 1987) e as inovações que contrariam o movimento consumerista causando, inclusive, prejuízos ao meio ambiente (OTTMAN, 1994).

Pressões ideológicas ilegítimas têm obstruído e ofuscado a real utilidade ou pertinência de inovações, que também por isso são ignoradas, evitadas ou rejeitadas, pois são inovações lastreadas em ações de "marketing social" manipulativo servindo a interesses corporativos.

Ram e Sheth justificam que as barreiras psicológicas são fundamentais na difusão de inovações. Propõem uma série de estratégias de marketing para viabilizar a aceitação das inovações, inclusive a do agente inovador: "Respeitar as tradições e normas dos usuários e perceber que ajustar-se com a situação é a melhor solução possível" (1989, p. 13).

\section{Contribuições substantivas de Rogers}

Ao discorrer sobre modelos, pesquisas e estudos de difusão de inovações, Rogers tem contribuído sobremaneira com diversas áreas do conhecimento, inclusive a comunicação social. Por ser um campo complexo e abrangente, seria difícil qualquer autor não merecer críticas e reparos a sua obra, o que fizemos até aqui.

Porém, mesmo em pontos polêmicos e discutíveis, é possível registrar contribuições significativas que Rogers apresenta na sua obra Diffusion of Innovations.

Um desses pontos se refere ao tratamento processual e sistêmico que Rogers atribui à difusão de inovação; ou seja, ele se afasta da concepção de que uma inovação é algo pontual. Segundo o autor, conquanto seja mais simples para os acadêmicos em difusão investigar a extensão de cada inovação como um evento independente, isso é uma distorção da realidade.

Uma contribuição substantiva de Rogers se refere ao conceito de "reinvenção", que seria o grau que uma inovação é mudada ou modificada por um usuário no processo de adoção e implementação. Para o autor, uma inovação não é necessariamente invariável durante o processo de sua difusão e o adotante não tem necessariamente um papel passivo.

Segundo Wilton, o receptor precisa ser visto como entidade contextualizada num espaço individual e coletivo: "Tais espaços são ao mesmo tempo de ne- gociação e de debates, já que os valores, longe de serem expressão de sentido dado apenas pelo produtor ou pelo receptor, são o que exprimem o processo mesmo no qual eles ocorrem" (1995, p. 35-36).

Rogers também faz incursões interessantes no campo da mídia e do jornalismo. Segundo o autor, um dos enfoques dos estudos de comunicação tem sido o estudo da difusão de eventos noticiosos, caso da morte da princesa Diana, assassinatos de líderes nacionais e desastres, como o da espaçonave Challenger e os ataques terroristas de 11 de setembro. Parafraseando Rogers:

Uma característica dos eventos noticiosos é que eles se difundem mais rapidamente que outras inovações. Fatos como o assassinato do presidente Kennedy, explosão da espaçonave Challenger e os ataques de 11 de setembro foram conhecidos por significativa quantidade de pessoas em pouco tempo, algo possível pelo noticiário. Essa rapidez ocorre porque o individuo precisa apenas obter conhecimento do evento noticiado, enquanto a adoção de inovações tecnológicas precisam de conhecimento, persuasão, decisão e implementação para seu processo decisório. Nessas situações, tais eventos encontram espaço noticioso interrompendo programações e as gráficas param de rodar os jornais para inserir esses eventos no conteúdo a ser levado ao público. Pessoas estranhas comentam esses eventos com outras que não conhecem (tradução livre, p.75-76).

Tudo isso, segundo Rogers, mostra como a difusão pelos meios massivos é importante até chegar nos meios inter-pessoais. Essa rapidez com que se propagam os fatos pelo noticiário é difícil de ser estudada, sendo uma das técnicas a "Pesquisa Firehouse" (usada por Deutschmann e Danielson, segundo Rogers), em que muitas pessoas fazem contato por telefone até 24 horas depois do evento a fim de saber quantos conhecem e como foi a repercussão do evento.

Para Cébirán (1999), a Guerra do Golfo (ocorrida em 1991) trouxe um marco para as transmissões de $\mathrm{TV}$, proporcionando que emissoras como a americana CNN enviasse imagens e sons em tempo real ao das ações da invasão dos EUA ao Iraque, envio esse proporcionado pelas novas tecnologias associadas ao uso de satélites.

Porém, a Internet incrementa ainda mais o potencial de transmitir novas informações, ampliando a capacidade de um fato ou fenômeno ser conhecido de forma mais imediata por diferentes públicos, inclusive pela convergência das mídias, caso da televisão com a Internet (CÉBIRÁN, 1999).

No entanto, aqui também cabem ressalvas ao trabalho de Rogers, uma vez que o autor não tece críticas sobre a cobertura jornalística de eventos políti- 
cos e bélicos. O mesmo se aplica no caso do jornalismo científico (OLIVEIRA, 2002), em que muitos veículos de comunicação passam conteúdos alinhados com certas ideologias e interesses políticos desviando o real sentido da ciência ou inovação de um sentido social.

\section{Considerações finais}

A obra Diffusion of Innovations, um dos estudos referenciais sobre difusão da informação e comunicação, tem sido considerada "modelar" por muitos pesquisadores. Apreciando criticamente tal obra, discorremos sobre o patamar dos estudos de difusão de inovação oferecido por Rogers e, com isso, analisamos sua pertinência com referenciais epistemológicos atuais e do campo da comunicação social.

Nossa análise crítica apresentou muitas considerações que podem merecer reservas quanto a uma aplicação automática em trabalhos no campo da difusão de inovações, mas também propiciou uma visão de que a contribuição de Rogers deve estar em permanente construção.Embora o próprio autor tenha o cuidado de não denominar seus estudos de difusão de inovações como "teoria", consideramos que há espaço para que um conjunto de pesquisadores possam construir parâmetros sustentáveis para uma teoria da difusão de inovações a fim de que esse campo tenha um tratamento mais sistematizado tanto para a comunicação social como outras áreas do conhecimento humano. mamecos

\section{REFERÊNCIAS}

BERLO, D.K. O processo da comunicação: introdução à teoria e à prática. São Paulo: Martins Fontes, 1999.

BLACKWELL, R.D.; MINIARD P.W; ENGEL, J.F. Comportamento do consumidor. São Paulo: Thomson, 2005.

BOCK, A.M.B. et al. Psicologias: uma introdução ao estudo de psicologia. São Paulo: Saraiva, 2001.

BOUDON, R; BOURRICAUD, F. Dicionário crítico da sociologia. São Paulo: Ática, 2001.

CEBRIÁN, Juan Luis. A rede: como nossas vidas serão transformadas pelos novos meios de comunicação. São Paulo: Summus, 1999.

DeFLEUR, Melvin; BALL-ROKEACH, Sandra. Teorias da Comunicação de Massa. Rio de Janeiro: Zahar, 1993.

FRANK, Kenneth; ZHAO, Yong; BORMAN, Kathryn. Social Capital and the Diffusion of Innovations Within Organizations: The Case of Computer Technology in Schools. Sociology of Education. Albany: V.77, N. 2; Apr 2004, p.148-171.
GALBRAITH, J. K. A sociedade afluente. São Paulo: Pioneira, 1987.

HARGIE, Colin; TOURISH, Dennis. Corporate communication in the management of innovation and change. Corporate Communications. Bradford. V.1, n.2, p. 3, 12p., 1996.

HARTLEY, Robert F. Errores en el marketing. Madrid: Paraninfo, 1990.

HAUG, Wolfgang Fritz. Crítica da estética da mercadoria. São Paulo: UNESP, 1997.

HOCKENBURY, D.; HOCKENBURY, S.E. Descobrindo a psicologia. São Paulo: Manole, 2003.

LEE, Jinkook; SCHUMANN, David W. The influence of communication source and mode on consumer adoption of technological innovations. The Journal of Consumer Affairs. Madison. V. 36, n. 1, p. 1, 27 p., Summer 2002.

MATTELART, Armand e MATTELART, Michele. História das teorias da comunicação. São Paulo: Loyola, 1999.

McQUAIL, Denis. Mass Communication Theory: an introduction. 3 ed. Londres: Sage, 1994.

OLIVEIRA, F. Jornalismo científico. São Paulo: Contexto, 2002.

OTTMAN, Jacquelyn A. Marketing Verde. São Paulo: Makron, 1994.

RAM, Sundaresan; SHETH, Jagdish N. Consumer resistance to innovations: the marketing problem and its solutions. The journal of consumer marketing. V. 6, n. 2, p.5-14, Spring 1989.

ROGERS, Everett M. Diffusion of innovations. 5ed. Nova York: Free Press, 2003.

SURRY, Daniel W. Diffusion Theory and Instructional Technology. Annual Conference of the Association for Educational Communications and Technology (AECT). Albuquerque, New Mexico. Feb 12 - 15, 1997. Disponível em http:// intro.base.org/docs/diffusion/ / Acesso em 23/ 05/2005.

STRAUBHAAR, J.; LaROSE, ROBERT. Comunicação, mídia e tecnologia. São Paulo: Thomson, 2004.

WILTON de SOUZA, Mauro. Recepção e comunicação: a busca do sujeito. In Sujeito, o lado oculto de receptor. WILTON de SOUZA, M. (Org.). São Paulo: Brasiliense, 1995. P. 13-38. 